\title{
PRISUSTVO PATOGENIH BAKTERIJA NA MEMBRANAMA STETOSKOPA U DOMU ZDRAVLJA „SAVSKI VENAC“ U BEOGRADU
}

\author{
Stefan Bošković́ ${ }^{1}$, Branislava Savić ${ }^{2}$
}

\author{
${ }^{1}$ Medicinski fakultet Univerziteta u Beogradu \\ ${ }^{2}$ Mentor; Institut za mikrobiologiju i imunologiju, Medicinski fakultet Univerziteta u Beogradu
}

Sažetak

Zaključak: Membrane stetoskopa bi trebalo dezinfikovati posle pregleda svakog pacijenta i sprovesti edukaciju lekara o značaju dezinfekcije stetoskopa.

Uvod: Prilikom pregleda pacijenata membrana stetoskopa može biti kontaminirana mikroorganizmima kože. Ako se stetoskopi ne dezinfikuju, mogu predstavljati izvor bolničkih infekcija.

Cilj: Cilj ovog rada je da se utvrdi stepen kontaminacije i identifikuju prisutni mikroorganizmi na membranama stetoskopa u Domu zdravlja "Savski venac" u Beogradu, u zavisnosti od toga da li su membrane dezinfikovane ili ne.

Materijal i metode: Brisevi su uzeti sa membrana 40 stetoskopa, od kojih je 33 pripadalo lekarima opšte medicine, a 7 pedijatrima. Lekari su dali podatke o dezinfekciji svojih stetoskopa. Materijal je zasejan na krvni agar i u dekstrozni bujon i inkubiran je na $37^{\circ} \mathrm{C}$ tokom 48h. Nakon porasta kolonija izvršena je identifikacija na osnovu mikroskopskih, kulturelnih i biohemijskih osobina. Antibiogram je rađen disk difuzionom metodom na Müller-Hinton agaru.

Rezultati: Trideset (91\%) lekara opšte medicine ne dezinfikuje svoje stetoskope, 3 (9\%) to čini jednom dnevno, a pedijatri svoje stetoskope dezinfikuju pre pregleda beba ili nakon deteta sa jasno vidljivom kožnom promenom. Svi stetoskopi su bili kontaminirani, nije bilo statistički značajne razlike između lekara opšte medicine i pedijatara, kao ni između lekara opšte medicine koji stetoskope brišu jednom dnevno i onih koji to ne čine $(p>0,05)$. Izolovane su samo bakterije i pripadaju rodovima Staphylococcus, Bacillus, Streptococcus, Enterococcus i Corynebacterium. Jedan izolat je identifikovan kao meticilin-osetljiv Staphylococcus aureus. Od 35 koagulaza negativnih stafilokoka, 4 izolata $(11,4 \%)$ su pokazala rezistenciju na meticilin a 2 izolata su bila multirezistentna.

Ključne reči: stetoskop, koagulaza negativni stafilokok, rezistencija na meticilin.

\section{Abstract}

Conclusion: Stethoscopes should be desinfected before examining each patient and further education of physicians on the subject is needed.

Introduction: During examination of patients the stethoscope membrane can be contaminated with the skin microorganisms. If the stethoscopes are not desinfected, they can become a source of nosocomial infections.

The Aim: The aim of this study is to determine the level of contamination and identify the present microorganisms on stethoscope membranes in „Savski venac" health center in Belgrade, disinfected or not.

Material and methods: Swabs were taken from 33 primary care physicians and 7 pediatricians. Blood agar and dextrose broth were used to grow bacteria and identification was based on microscopic, cultural and biochemical characteristics. Amtimicrobial susceptibility was tested using disc diffusion on Müller-Hinton agar.

Results: Thirty (91\%) of primary care physicians do not clean their stethoscopes, $3(9 \%)$ do it daily, and pediatricians clean them before examining a baby or after examining a child with clearly visible skin lesions. All stethoscopes were contaminated and there was no statistically significant difference in contamination between primary care physicians who clean their stethoscopes and those who do not, nor between primary care physicians and pediatricians. The isolates belong to genera Staphylococcus, Bacillus, Streptococcus, Enterococcus and Corynebacterium. One methicillin-susceptible Staphylococcus aureus was isolated. Out of 35 coagulase negative Staphylococci, $4(11,4 \%)$ were resistant to methicillin (MRCoNS). Two out of 4 MRCoNS were multidrug resistant.

Key words: stethoscope, coagulase negative Staphylococci, methicillin resistance. 


\section{Uvod}

Stetoskop, kao sredstvo za rad svih lekara opšte medicine i pedijatrije, dolazi u kontakt sa kožom pacijenata i membrana se kontaminira mikroorganizmima kože. Ako se membrana stetoskopa ne dezinfikuje između dva pregleda, mikroorganizmi na njoj mogu preživeti i mogu se preneti na drugog pacijenta. Kontaminirani stetoskopi mogu predstavljati izvor bolničkih infekcija [1].

U većini istraživanja dominantni izolati na stetoskopima su koagulaza negativne stafilokoke (CoNS) [2]. Iako neki autori zanemaruju prisustvo CoNS, jer čine fiziološku mikrofloru kože, nihov značaj je veliki ukoliko su rezistentne na meticilin (meticilin rezistentne koagulaza negativne stafilokoke - MRCoNS), pošto mogu preneti gene za rezistenciju na prethodno meticilin osetljive sojeve. U nekim istraživanjima prisustvo Staphylococcus aureus i Gram negativnih bakterija (Pseudomonas spp.) označava se kao teška bakterijska kontaminacija [3].

Bolničke infekcije predstavljaju veliki problem zdravstvenog sistema od osnivanja prvih bolnica pa do danas. Dezinfekcija membrana stetoskopa jedna je od mera za sprečavanje ovih infekcija. Neophodna je edukacija zdravstvenih radnika u cilju sprovođenja ove mere prevencije bolničkih infekcija.

Cilj ovog rada je da se utvrdi stepen kontaminacije i identifikuju prisutni mikroorganizmi na membranama stetoskopa u Domu zdravlja „Savski venac“ u Beogradu, u zavisnosti od toga da li su membrane dezinfikovane ili ne.

\section{Materijal i metode}

Brisevi su uzeti sa membrana 40 stetoskopa, od kojih je 33 pripadalo lekarima opšte medicine, a 7 pedijatrima. Obuhvaćeni su svi lekari opšte medicine i 7 od 8 pedijatara. Uzorkovanje je izvršeno 3. i 4. februara 2014. godine pred kraj radnog vremena $\mathrm{u}$ obe smene $\mathrm{u}$ svim zdravstvenim stanicama Doma zdravlja i tom prilikom lekari su dali podatke o redovnosti i načinu čišćenja svojih stetoskopa. Za izvođenje ovog ispitivanja dobijena je saglasnost od uprave Doma zdravlja "Savski venac“.

Pre uzorkovanja brisevi su umočeni u sterilan fiziološki rastvor, a zatim su membrane prebrisane celom površinom, poštujući metode sterilnog rada. Transport do laboratorije trajao je manje od 2 sata. Po dopremanju u laboratoriju materijal je zasejan u dekstrozni bujon i na krvni agar. Zasejane podloge su inkubirane na $37^{\circ} \mathrm{C}$ do $48 \mathrm{~h}$. Nakon porasta, bakterijske kolonije su identifikovane na osnovu mikroskopskih, kulturelnih i biohemijskih osobina. Korišćeno je bojenje po Gramu, test za dokazivanje produkcije slobodne koagulaze i test hi- drolize eskulina [4]. Na osnovu broja izolovanih bakterijskih vrsta određivan je stepen kontaminacije na sledeći način: do dve izolovane bakterijske vrste predstavljale su nizak stepen kontaminacije, tri bakterijske vrste umeren stepen kontaminacije, a četiri i više vrsta visok stepen kontaminacije [5].

Meticilinska rezistencija je ispitivana pomoću diska cefoksitina $(30 \mu \mathrm{g})$. Za izolovane sojeve koji pripadaju rodu Staphylococcus rađen je antibiogram na Müller-Hinton agaru disk difuzionom metodom. Ploče su inkubirane $24 \mathrm{~h}$ na $35 \pm 2^{\circ} \mathrm{C}$. Interpretacija je vršena na osnovu merenja prečnika zone inhibicije rasta i kriterijuma koje daje Evropski komitet za ispitivanje osetljivosti na antimikrobne lekove (engl. The European Committee on Antimicrobial Susceptibility Testing, EUCAST) [6]. Za izolovane vrste Staphylococcus aureus i koagulaza negativne meticilin rezistentne izolate ispitivana je osetljivost i na druge antibiotike: eritromicin $(15 \mu \mathrm{g})$, klindamicin $(2 \mu \mathrm{g})$, vankomicin $(30 \mu \mathrm{g})$, tetraciklin $(30 \mu \mathrm{g})$, trimetoprim-sulfametoksazol $(1,25 \mu \mathrm{g} / 23,75 \mu \mathrm{g})$, gentamicin $(10 \mu \mathrm{g})$, ciprofloksacin $(5 \mu \mathrm{g})$, hloramfenikol $(30 \mu \mathrm{g})$, rifampicin $(5 \mu \mathrm{g})$, linezolid $(10 \mu \mathrm{g})$ i fusidinsku

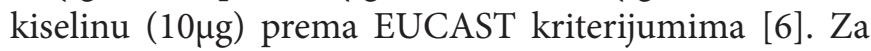
Stapylococcus aureus dodatno je ispitivana i rezistencija na penicilin $(6 \mu \mathrm{g}, 10 \mathrm{IU})$. Proizvođač svih antibiotika korišćenih za antibiogram je Bio-Rad iz Francuske.

Kao kontrolni soj za antibiogram korišćen je Staphylococcus aureus ATCC 29213. Kriterijum za identifikaciju multirezistentnih sojeva bio je rezistencija na 3 i više grupa antibiotika [7].

Statistička analiza je urađena koristeći Fišerov test tačne verovatnoće.

\section{Rezultati}

Od 33 lekara opšte medicine čiji su stetoskopi ispitivani, 30 (91\%) ne dezinfikuje svoje stetoskope, a 3 (9\%) to čini jednom dnevno koristeći 70\% etanol. Pedijatri (njih 7) svoje stetoskope dezinfikuju pre pregleda novorođenčeta ili posle pregleda deteta sa varičelom ili nekom jasno vidljivom kožnom promenom, takođe koristeći $70 \%$ etanol. Kao najčešće razloge za nečišćenje stetoskopa lekari navode nedostatak vremena, zaboravnost i u retkim slučajevima nedostatak dezinficijenasa. Razlozi za izostanak dezinfekcije stetoskopa prikazani su na grafikonu 1.

Do zamućenja bujona i porasta bakterijskih kolonija došlo je u svim ispitivanim uzorcima. Nije uočena statistički značajna razlika $(\mathrm{p}>0,05)$ u kontaminaciji stetoskopa između lekara opšte medicine koji ne brišu svoje stetoskope i onih koji to čine jednom dnevno, kao ni između stetoskopa lekara opšte medicine i stetoskopa 
pedijatara.

Nizak stepen kontaminacije prisutan je na 38 stetoskopa, umeren na 2, dok visok stepen kontaminacije nije primećen. Stepen kontaminacije stetoskopa prikazan je na grafikonu 2. Nije primećena statistički značajna razlika između stepena kontaminacije i redovnosti čišćenja $(\mathrm{p}>0,05)$.

Grafikon 1. Razlozi za izostanak dezinfekcije membrana stetoskopa.

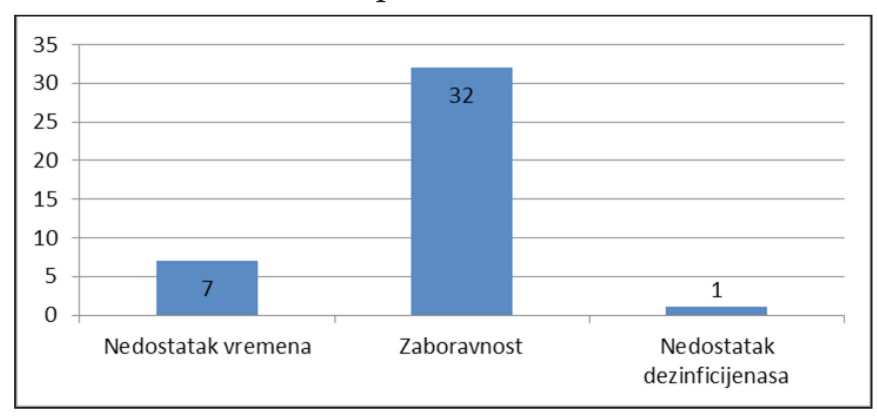

Grafikon 2. Stepen kontaminacije stetoskopa.

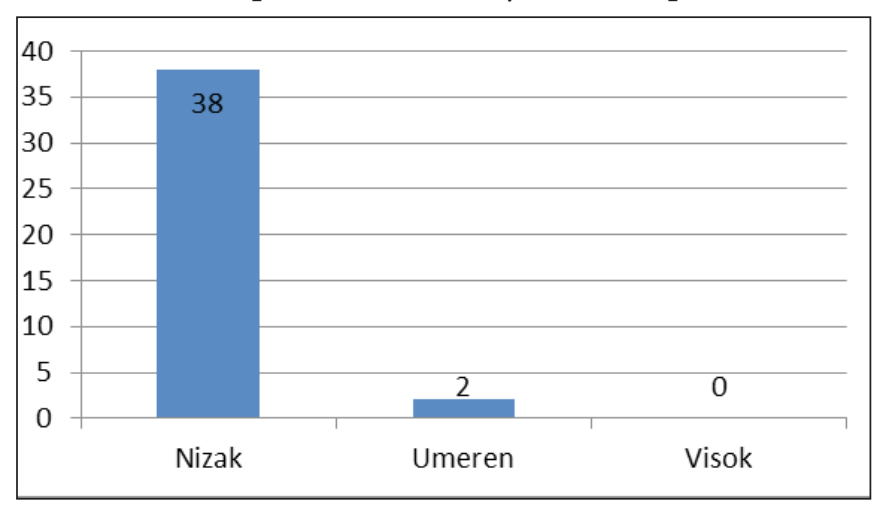

Izolovane vrste pripadaju rodovima Staphylococcus (na 36 stetoskopa), Enterococcus (na 11 stetoskopa), Streptococcus (na 4 stetoskopa), Bacillus (na jednom stetoskopu) i Corynebacterium (na 10 stetoskopa). Učestalost izolovanih vrsta bakterija prikazana je u tabeli 1.

Izolovani Staphylococcus aureus je bio osetljiv na meticilin, rezistentan na penicilin i osetljiv na ostale ispitivane antibiotike. Staphylococcus aureus je izolovan sa membrane stetoskopa na odeljenju pedijatrije.

Za koagulaza negativne stafilokoke ispitivana je osetljivost na cefoksitin i za izolate koji su pokazali rezistenciju urađen je antibiogram i na ostale antbiotike. Od 35 koagulaza negativnih stafilokoka, četiri su pokazala rezistenciju na cefoksitin ili $11,4 \%$. Svi uzorci potiču od lekara specijalista opšte medicine.

Od 35 koagulaza negativnih stafilokoka dva su multirezistentna, što iznosi $5,7 \%$, prvi je pokazao rezistenciju prema $\beta$-laktamskim antibioticima, makrolidima, linkozamidima, inhibitorima metabolizma folata, aminoglikozidima, fluorohinolonima i prema hloramfenikolu, a drugi prema $\beta$-laktamskim antibioticima, makrolidima, linkozamidima, inhibitorima metabolizma folata, aminoglikozidima i fluorohinolonima.

\section{Diskusija}

U ovom istraživanju ustanovljeno je da lekari opšte medicine i pedijatri, zaposleni u Domu zdravlja „Savski venac“, ne dezinfikuju svoje stetoskope dovoljno često i da čišćenje jednom dnevno i način čišćenja koji praktikuju pedijatri ne prave nikakvu razliku u stepenu kontaminacije. Lekari koji dezinfikuju svoje stetoskope, trebalo bi to da čine u skladu sa preporukama vodiča Centra za kontrolu i prevenciju bolesti (engl. Centers for Disease Control and Prevention - CDC) [8]. Dobijeni podaci u skladu su sa navodima iz literature $[2,5,9]$.

Samo sa membrane jednog stetoskopa izolovana je patogena vrsta bakterija (Staphylococcus aureus). Izolovane bakterije sa membrana stetoskopa su uslovno patogene. Dominantne koagulaza negativne stafilokoke deo su fiziološke mikroflore kože, što odgovara upotrebi stetoskopa, a vrste koje pripadaju rodu Enterococcus predstavljaju indikatore fekalnog zagađenja. Izolovane vrste su takođe u skladu sa literaturom i podaci pokazuju da membrana stetoskopa predstavlja pogodnu sredinu za preživljavanje bakterija $[2,5,9]$.

O prisustvu meticilin rezistentnih stafilokoka na stetoskopima nema puno podataka. Radovi pokazuju da je prisustvo meticilin rezistentnih koagulaza negativnih stafilokoka u bolničkoj sredini oko $30 \%$ od svih izolovanih koagulaza negativnih stafilokoka $[10,11]$. S obzirom na to da je ovo istraživanje sprovedeno $u$ ambulantnim uslovima, što spada u vanbolničku sredinu, može se

Tabela 1. Učestalost izolacije različitih bakterija na stetoskopima.

\begin{tabular}{|l|l|l|l|l|l|l|}
\hline \multicolumn{7}{|c|}{ Vrsta bakterija } \\
\hline \multirow{3}{*}{$\begin{array}{l}\text { Broj } \\
\text { stetoskopa }\end{array}$} & $\begin{array}{l}\text { Staphylococcus } \\
\text { aureus }\end{array}$ & $\begin{array}{l}\text { Koagulaza } \\
\text { negativne } \\
\text { stafilokoke }\end{array}$ & $\begin{array}{l}\text { Enterococcus } \\
s p .\end{array}$ & $\begin{array}{l}\text { Alfa } \\
\text { hemolitičke } \\
\text { streptokoke }\end{array}$ & Bacillus sp. & $\begin{array}{l}\text { Corynebacterium } \\
\text { sp. }\end{array}$ \\
\cline { 2 - 7 } & $1(2,5 \%)$ & $35(87,5 \%)$ & $11(27,5 \%)$ & $4(10 \%)$ & $1(2,5 \%)$ & $10(25 \%)$ \\
\hline
\end{tabular}


reći da je prisustvo $11,4 \%$ meticilin rezistentnih stafilokoka prihvatljivo u odnosu na bolničku sredinu, gde je broj meticilin rezistentnih stafilokoka dosta veći.

Iako je sa kliničke tačke gledišta prisustvo meticilin rezistentnog Staphylococcus aureus (MRSA) mnogo značajnije nego MRCoNS, ne može se zanemariti značaj ovih vrsta kao rezervoara gena za rezistenciju prema antimikrobnim lekovima. Kao što pokazuju rezultati ovog istraživanja, pored rezistencije prema $\beta$-laktamskim antibioticima, MRCoNS su pokazali rezistenciju i prema drugim antimikrobnim lekovima. Zbog čestog transfera mikroorganizama iz vanbolničke u bolničku sredinu i obrnuto, prisustvo MRCoNS povećava rizik za izazivanje intrahospitalnih infekcija [12].

Iz rezultata ovog istraživanja proizlazi da je neredovno čišćenje stetoskopa nedovoljno i treba ih dezinfikovati nakon pregleda svakog pacijenta. Takođe, potrebno bi bilo sprovesti edukaciju lekara o načinu dezinfekcije stetoskopa i ukazati na njen značaj. Na taj način bi se smanjila mogućnost transfera potencijalno patogenih bakterija sa jednog pacijenta na drugog, kao i sa primarnog nivoa zdravstvene zaštite na sekundarni i tercijarni nivo.

\section{Literatura}

1. Neely AN, Maley MP. Survival of enterococci and staphylococci on hospital fabrics and plastic. J Clin.Microbiol 2000; 38:724-726.

2. Zuliani-Maluf ME, Maldonado AF, Bercial ME, Pedroso SA. Stethoscope: a friend or an enemy? Sao Paulo Med J 2002; 120:13-15.

3. Uneke CJ, Ogbonna A, Oyibo PG, Onu CM. Bacterial contamination of stethoscopes used by health workers: public health implications. J Infect Dev Ctries 2010; 4:436-41.

4. Mahon CR, Lehman DC, Manuselis G. Textbook of diagnostic microbiology. Maryland Heights, MO: Saunders/ Elsevier; 2010.

5. Wilkins R, Restrepo R, Bourne K, Daher N. Contamination level of stethoscopes used by physicians and physician assistants. J Physician Assist Educ 2007; 18:41-43.

6. The European Committee on Antimicrobial Susceptibility Testing. Breakpoint tables for interpretation of MICs and zone diameters. 2013; Version 3.1. Available from: http:// www.eucast.org.

7. Magiorakos AP, Srinivasan A, Carey RB et al. Multidrug-resistant, extensively drug-resistant and pandrug-resistant bacteria: an international expert proposal for interim standard definitions for acquired resistance. Clin Microbiol Infect 2012; 18:268-281.

8. Rutala WA, Weber DJ; The Healthcare Infection Control Practices Advisory Committee (HICPAC). CDC Guideline for Disinfection and Sterilization in Healthcare Facilities. 2008; Available from: http://www.cdc.gov/hicpac/ pdf/guidelines/disinfection_nov_2008.pdf

9. Youngster I, Berkovitch $\bar{M}$, Heyman E, Lazarovitch Z, Goldman M. The stethoscope as a vector of infectious diseases in the paediatric division. Acta Paediatr 2008; 97:1253-1255.

10. Shobha KL, Rao PS, Thomas J. Survey of Staphylococcus isolates among hospital personnel, environment and their antibiogram with special emphasis on methicillin resistance. Indian J Med Microbiol 2005; 23:186-8.

11. Leontsini F, Papapetropoulos A, Vantarakis A. Stethoscopes as vectors of multi-resistant coagulase negative staphylococci in a tertiary hospital. Int J Med Sci Public Health 2013; 2:324-329.

12. Stepanović S, Ćirković I, Djukić S, Vuković D, Švabić-Vlahović M. Public transport as a reservoir of methicillin-resistant staphylococci. Lett Appl Microbiol 2008; 47:339341. 